NBER WORKING PAPER SERIES

\title{
THE PREDICTIVE CONTENT OF ENERGY FUTURES: AN UPDATE ON PETROLEUM, NATURAL GAS, HEATING OIL AND GASOLINE
}

\author{
Menzie D. Chinn \\ Michael LeBlanc \\ Olivier Coibion \\ Working Paper 11033 \\ http://www.nber.org/papers/w11033
NATIONAL BUREAU OF ECONOMIC RESEARCH
1050 Massachusetts Avenue
Cambridge, MA 02138
January 2005

We thank Yin-Wong Cheung, Fred Joutz, Simon van Norden, Bob Weiner and Jeffrey Williams for very useful comments. This paper draws upon work conducted while the authors were staff members of the Council of Economic Advisers. None of the conclusions should be interpreted as representing the views of the U.S. Government or any other institutions the authors are affiliated with.The views expressed herein are those of the author(s) and do not necessarily reflect the views of the National Bureau of Economic Research.

(C) 2005 by Menzie D. Chinn, Michael LeBlanc, and Olivier Coibion. All rights reserved. Short sections of text, not to exceed two paragraphs, may be quoted without explicit permission provided that full credit, including $($ ) notice, is given to the source. 
The Predictive Content of Energy Futures: An Update on Petroleum, Natural Gas, Heating Oil and Gasoline

Menzie D. Chinn, Michael LeBlanc, and Olivier Coibion

NBER Working Paper No. 11033

January 2005

JEL No. G13, Q43

\title{
$\underline{\text { ABSTRACT }}$
}

This paper examines the relationship between spot and futures prices for energy commodities (crude oil, gasoline, heating oil markets and natural gas). In particular, we examine whether futures prices are (1) an unbiased and/or (2) accurate predictor of subsequent spot prices. We find that while futures prices are unbiased predictors of future spot prices, with the exception those in the natural gas markets at the 3-month horizon. Futures do not appear to well predict subsequent movements in energy commodity prices, although they slightly outperform time series models.

\author{
Menzie D. Chinn \\ Department of Economics \\ University of Wisconsin \\ 1180 Observatory Drive \\ Madison, WI 53706 \\ and NBER \\ mchinn@lafolette.wisc.edu \\ Michael LeBlanc \\ Economic Research Service \\ 1800 M Street NW \\ Washington, DC 20036 \\ mleblanc@ers.usda.gov \\ Olivier Coibion \\ Department of Economics \\ University of Michigan \\ 238 Lorch Hall \\ 611 Tappan Street \\ Ann Arbor, MI 48109 \\ ocoibion@umich.edu
}


In September of 2004, the price of oil broke the record of $\$ 50$. Analysts predicted a sustained period of elevated petroleum prices, a natural conclusion given the growing world demand for petroleum products and the tight capacity constraints. Since then, oil prices have fallen below the levels predicted by petroleum futures. It is natural at this juncture to ask whether judgmental forecasts or market based indicators - such as futures prices - are superior predictors.

This paper examines the relationship between spot and futures prices for energy commodities. In particular, we examine whether futures prices are (1) an unbiased and/or (2) accurate predictors of subsequent spot prices, in the markets for crude oil, natural gas, gasoline, and heating oil.

In our view, a re-examination is warranted because of recent public policy concerns about sharp movements in energy prices that have macroeconomic and international repercussions (see for instance Hunt et al., 2001; LeBlanc and Chinn, 2004). Figure 1 illustrates the wide swings that have occurred in the price of petroleum over the past two decades. The most recent of these movements occurred in the last few years. From a low of $\$ 11$ per barrel at the end of November 1998, crude oil prices rose to almost \$34 in November of 2000. Price movements were even more dramatic in the natural gas market. They rose from $\$ 1.98$ at the end of 1998 to over $\$ 10$ at the end of 2000. If futures prices correctly anticipate the direction of these movements on average, then public policy can be based upon such market information. ${ }^{1}$ On the other hand, if futures prices are misleading indicators of future price movements, then policy-makers 
should take into account the deficiencies of futures prices as price predictors, and either appeal to alternative forecasting devices, or undertake public policies to mitigate the effects of energy price uncertainty.

To illustrate this point, consider the situation at the beginning of 2001. Certain policy makers were arguing for a policy of encouraging domestic production of petroleum, in light of the then high prices of crude oil in order to drive down prices. ${ }^{2}$ However, in the absence of externalities, if individuals and firms can make "good" forecasts of prices, then hedging activities can nullify arguments for public policy interventions of this nature. Interestingly, at the end of March 2001, March 2002 futures were trading at $\$ 25.04 / \mathrm{barrel}$, almost exactly equal to average price of $\$ 24.28$ actually recorded for that month. Of course, one anecdote does not constitute a proof, so in this paper we undertake a systematic analysis of the issue.

To anticipate the results, we find that the informational content of futures prices varies with commodity. Specifically, futures prices are unbiased predictors of future spot prices in the petroleum, gasoline and heating oil markets. In contrast natural gas futures prices are a biased predictor of subsequent spot prices at the 3- and 6-month horizons. While the proportion of variation in price changes explained by futures prices is not typically very large, the forecasting performance of futures prices often exceeds that of optimally selected time series models, over the January 1999 to October 2004 period.

\footnotetext{
${ }^{1}$ Greenspan (2004) has appealed to long dated futures as predictors of petroleum prices. While there is some dispute as to whether such futures have much informational content (Baum, 2004), we focus on futures with maturities within one year.

${ }^{2}$ One recent example is outlined in The Report of the National Energy Policy Development Group (Executive Office of the President, 2001).
} 


\section{Theory and Previous Literature}

The notion that the futures price is the optimal forecast of the spot price is an implication of the efficient market hypothesis. In an efficient market, new information is reflected instantly in commodity prices. If this is true, then price patterns are random, and no system based on past market behavior can do other than break even. The link between efficiency and forecastability arises from realizing the difference between the current futures price and the future spot price represents both the forecasting error and the opportunity gain or loss realized from taking certain positions. The requirement that the forecasting error is zero on average is consistent with both market efficiency (the absence of profitable arbitrage opportunities) and the unbiasedness property of the forecaster (zero forecasting error on average).

The futures price of a storable commodity such as crude oil is determined by the spot price and the cost incurred while the commodity is stored awaiting delivery some time in the future. The cost associated with holding the commodity until the delivery date is known as the cost-of-carry. The cost-of-carry consists of the cost of storing oil in a tank (and perhaps insurance) and the financial cost in the form of the opportunity cost of holding oil, or the cost of funding, and perhaps a risk premium.3

The spot/futures pricing relationship is based on the assumption that market participants are able to trade in the spot and futures markets simultaneously, i.e. they can utilize spot/futures arbitrage. The relationship between the futures rate and the current spot rate for petroleum is given by:

$$
f_{t \mid t-k}-s_{t-k}=d_{t \mid t-k}+Q_{t \mid t-k}
$$


where $f_{t \mid t-k}$ is the observed (log) time $\mathrm{t}-\mathrm{k}$ futures contract price that matures at time $\mathrm{t}$, and $s_{t-k}$ is the time t-k spot rate, $d_{t \mid t-k}$ the log cost-of-carry (the sum of storage costs minus convenience yield, plus interest costs and a risk premium), and $Q_{t \mid t-k}$ is a term accounting for the marking-to-market feature of futures. The object on the left hand side of (1) is called the "basis" in the commodity futures literature. ${ }^{4}$

If we assume the log spot rate follows a time random walk with drift, and expectations are rational, then the time t-k expectation of the change in the spot rate will equal the basis and the marking-to-market term. Hence, in the regression of change in the spot rate on the basis,

$$
s_{t}-s_{t-k}=\beta_{0}+\beta_{1}\left(f_{t \mid t-k}-s_{t-k}\right)+\varepsilon_{t}
$$

$\beta_{0}$ subsumes the terms in the right hand side of (1), as well as the parameters defining the time series process governing the spot rate, while $\beta_{1}=1$ if the basis is the optimal predictor of the change in the spot rate.

The literature examining the behavior of futures markets is fairly extensive. A number of studies have examined the efficiency of futures markets and have investigated the related issue of the forecastability of spot energy prices. Unsurprisingly, the conclusions are quite diverse. A number of studies provide evidence for efficient markets and an equally large number provide evidence that contradicts an efficient market (unbiased futures price prediction) interpretation. For example, Serletis (1991) found evidence consistent with efficient crude petroleum markets. Bopp and Lady (1991),

\footnotetext{
${ }^{3}$ Williams and Wright (1991) provide an excellent overview to the behavior of commodity prices and
} 
however, found that either the spot or the futures price can be the superior forecasting variable depending on market conditions, and the information content of the two price series is essentially the same.

The more recent literature has focused on the long-run properties of the spot and forward prices, in the context of cointegration. ${ }^{5}$ We focus on the change in the spot rate, and its relation to the basis, reserving the analysis of long run dynamics to future study.

\section{An Empirical Analysis}

\subsection{Overview of the Data}

We obtained data for four energy prices - petroleum (West Texas Intermediate, or WTI), natural gas (Henry Hub), gasoline (Gulf Coast), and heating oil (No. 2, Gulf

Coast). All the futures prices pertain to the New York Mercantile Exchange (NYMEX), as reported by Bloomberg.

Figures 2 through 5 depict the current spot and the futures price for 3 months ahead ( $s_{t}$ and $f_{t, 3}$ ) for each of these energy commodities. Due to the institutional nature of the crude oil market, the "current" price is measured by the one month futures price, as the "spot" price is for a delivery approximately one month later than the transaction.6 As is typical of futures prices, the implied future spot rate tracks the actual spot rate with a 3 month lag. This pattern is also evident at longer horizons, but is slightly less pronounced.

\footnotetext{
futures.

${ }^{4}$ The discussion and notation is based upon the exposition in Brenner and Kroner (1995).

${ }^{5}$ See for instance, Crowder and Hamed (1993), Moosa and Al-Loughani (1994), Herbert (1993) and Walls (1995).

${ }^{6}$ The one month future and spot are the same, except for some timing differences due to closing times in the spot and futures markets.
} 
Interestingly, an exception to the aforementioned pattern occurs when there are sharp spikes in the spot rate. Then - with the exception of the 1991 price increase - future rates tend to deviate from the spot rate. The most obvious instances of this phenomenon are for the 1996 and 2000 spikes in natural gas prices, and the 2000 spike in heating oil prices.

In order to evaluate more formally the properties of the relationship between the spot and futures prices, we now move to a statistical analysis.

\subsection{Estimation and Results}

Equation (2) is estimated using OLS using spot and futures prices sampled at a monthly frequency. These data are all sampled at the end of month, and hence allow proper synchronization of prices. Note however that because horizons of 3, 6 and 12 months are used, and the data is of monthly frequency, the regression residuals incorporate overlapping information. Under the null hypothesis of efficient markets (risk neutrality and rational expectations), the regression residuals will exhibit serial correlation. In order to obtain consistent estimates of the standard errors, necessary to conduct proper statistical inference, we calculate heteroskedasticity and serial correlation robust standard errors. ${ }^{7}$

The results are reported in Table 1. For the crude oil market, the estimates for $\beta_{1}$ at the 3,6 and 12-month horizons are not statistically distinguishable from unity. Hence, one cannot reject the efficient markets hypothesis. However, it is also true that in none of the cases are futures good predictors of subsequent spot prices. At the 3-month horizon, the basis accounts for only 5 percent of total variation in changes in spot rates; at the 12- 
month horizon, this proportion is only 10 percent. $^{8}$ Further note that even though the slope coefficient is near unity, the constant is fairly large - albeit not statistically significant - indicating that the basis points in the correct direction, but there is a natural drift up in the price change, even after accounting for other factors.

Natural gas futures appear to be a slightly more successful predictor of future spot prices, especially at the longer horizon. While the coefficient is quantitatively and statistically different from the posited value of unity at the 3 month horizon, at the other horizons, the slope coefficient is not statistically distinguishable from unity, and the proportion of variance explained exceeds 25 percent.

For gasoline futures, one cannot reject the possibility of $\beta_{1}$ being statistically indistinguishable from unity. However, as with crude oil markets, these futures are very poor predictors of subsequent prices. The adjusted $\mathrm{R}^{2} \mathrm{~s}$ are relatively low in these regressions, explaining only between $9 \%$ and $23 \%$ of total variation respectively. Moreover, the interpretation of the results using 12-month futures price series is complicated by the large and numerous gaps in the data series, which limits the number of observations to 115 .

Estimating the same equation for heating oil, we find that we cannot reject the market efficiency hypothesis for our three futures contracts. As with gasoline, the $\mathrm{R}^{2} \mathrm{~s}$ remain low, with 3, 6, and 12-month futures accounting for $15 \%, 13 \%$, and $17 \%$ of the variation in future spot prices.

\footnotetext{
${ }^{7}$ Using monthly data, if the futures mature 12 months (4 quarters) in the future, then a moving average process of $11(=12-1)$ is induced. The Newey-West standard errors are calculated using a Bartlett window and lag order set equal to the $2 \times(\mathrm{k}-1)$, following Cochrane (1991).

${ }^{8}$ The crude oil market possesses some unique institutional features. The most important is that it is not possible to truly effect a purchase on the spot market. Rather, toward the end of each month, delivery is arranged for something approaching one month in the future. Hence, the current 1-month futures price is
} 
The pattern of these results is apparently not dependent upon the sample encompassing the recent run-up in energy prices. If the sample is truncated at March 2001 , then similar results are obtained. One of the few differences is the finding of slightly more evidence of inefficiency in the natural gas futures market, with bias exhibited at two horizons ( 3 and 6 months). No substantive differences are detected in the other markets.

\section{Forecast Comparison}

We evaluate the relative forecasting abilities of two rules of thumb and a simple econometric model: the futures rate as a predictor, and the current spot rate as the best guess of the future rate, and a time series model. A description of how the model is selected and estimated is provided in the Appendix. The futures rate is used here as a simple predictor; the estimated relationships in Table 1 are not incorporated in these estimates. The $1999 \mathrm{~m} 01-2004 \mathrm{~m} 10$ period is used to compare the forecasts.

As indicated in Table 2, futures prices do a quite good job, in terms of both unbiasedness and smallest forecast errors, for both natural gas and gasoline. Futures also do well in terms of smallest errors for petroleum and heating oil, even though a random walk proves to be superior in terms of unbiasedness at short horizons.

In general, the predictors -- futures prices and time series models -- underpredict actual energy prices. This is partly true because of the pronounced upward drift in energy prices during the post-2001 period.

used as a measure of the true spot rate. If one uses the reported spot price instead, the predictive power of the basis is somewhat reduced. 
This pattern of results can be put into context by examining the visual depiction of the data. Figure 6 shows the crude oil price, the price predicted by the 12 month futures, and price predicted by the time series model and random walk. It is clear that neither the futures prices nor the time series models provide a tremendous amount of information about the actual path of petroleum prices.

\section{Conclusion}

- Futures prices are unbiased predictors of crude oil, gasoline, and heating oil prices, but not of natural gas prices at the 3 month horizon.

- Futures prices typically explain only a small proportion of the variation in underlying commodity price movements -- no more than 35 percent even at the 12 month horizon for natural gas.

- Time series models (relating a commodity price to lagged own prices, and estimated errors) do not fare any better -- and usually fare worse - than commodity futures prices as forecasts.

- A random walk characterization of commodity prices is not a particularly good one. This result contrasts with those found for other asset prices, notably foreign exchange rates. However, this result may partly be an artifact of our forecasting sample which encompasses a period of rising prices. 


\section{Appendix}

To generate the forecasts using time series models, the following algorithm was used.

1. An ARIMA $(1,1,1)$ is estimated.

2. Use the AIC to select the optimal lag length.

3. Estimate using the in-sample period (up to $1997 \mathrm{~m} 12$ ); then roll recursively the estimation until all the out-of-sample observations are exhausted.

4. Forecasts are compared on a 1999m01-2004m10 sample.

In an earlier version of this paper examining data ending in $2001 \mathrm{~m} 04$, petroleum prices were determined to be trend stationary, while the other prices were found to be difference stationary; as a consequence an $\operatorname{ARMA}(1,1)$ was used for petroleum and an $\operatorname{ARIMA}(1,1,1)$ for the other series. In this longer sample ending in $2004 \mathrm{~m} 10$, the stationarity findings are reversed. Given the ambiguity in the results, and the fact that all the series are nominal prices, we opt to assume all series are I(1). 


\section{References}

Baum, Caroline, 2004, "Greenspan's 2010 Space Odyssey with Oil Futures," Bloomberg.com (October 19).

Bopp, Anthony E. and George M. Lady, 1991, "A Comparison of Petroleum Futures versus Spot Prices as Predictors of Prices in the Future," Energy Economics 13(4):274282.

Brenner, Robin and Kenneth Kroner, 1995, "Arbitrage, Cointegration, and Testing the Unbiasedness Hypothesis in Financial Markets," Journal of Financial and Quantitative Analysis 30(1) (March), pp. 23-42.

Cochrane, John, 1991, "Production-Based Asset Pricing and the Link Between Stock Returns and Economic Fluctuations," Journal of Finance 46 (March) 207-234.

Crowder, William and Anas Hamed, 1993, "A Cointegration Test for Oil Futures Market Efficiency," Journal of Futures Markets 13(8), pp. 933-41.

Executive Office of the President, 2001, Report of the National Energy Policy Development Group (Washington, DC: U.S. GPO).

Greenspan, Alan, 2004, “Oil," Speech To the National Italian American Foundation, Washington, D.C. (October 15).

Herbert, John 1993, "The Relation of Monthly Spot to Futures Prices for Natural Gas," Energy 18(1), pp. 1119-1124.

Hunt, Benjamin, Peter Isard, and Douglas Laxton, 2001, “The Macroeconomic Effects of Higher Oil Prices," IMF Working Paper 01/14 (Washington, DC: IMF).

LeBlanc, Michael, and Menzie Chinn, 2004, "Do High Oil Prices Presage Inflation? Cross-Country Evidence,” Business Economics 39(2) (April).

Moosa, Imad and Nabeel Al-Loughani, 1994, "Unbiasedness and time varying risk premia in the crude oil futures market," Energy Economics 16(2), pp. 99-105.

Moosa, Imad and Nabeel Al-Loughani, 1995, "The Effectiveness of Arbitrage and Speculation in the Crude Oil Futures Market," The Journal of Futures Markets 15(2), pp. 167-186.

Serletis, Apostolos, 1991, "Rational Expectations, Risk and Efficiency in Energy Futures Markets," Energy Economics 13(2):111-115.

Walls, David W., 1995, "An Econometric Analysis of the Market for Natural Gas Futures,” Energy Journal 16(1): 71-83. 
Williams, Jeffrey and Brian Wright, 1991, Storage and Commodity Markets (Cambridge: Cambridge University Press). 
Table 1

Regressions of Price Change on the Basis

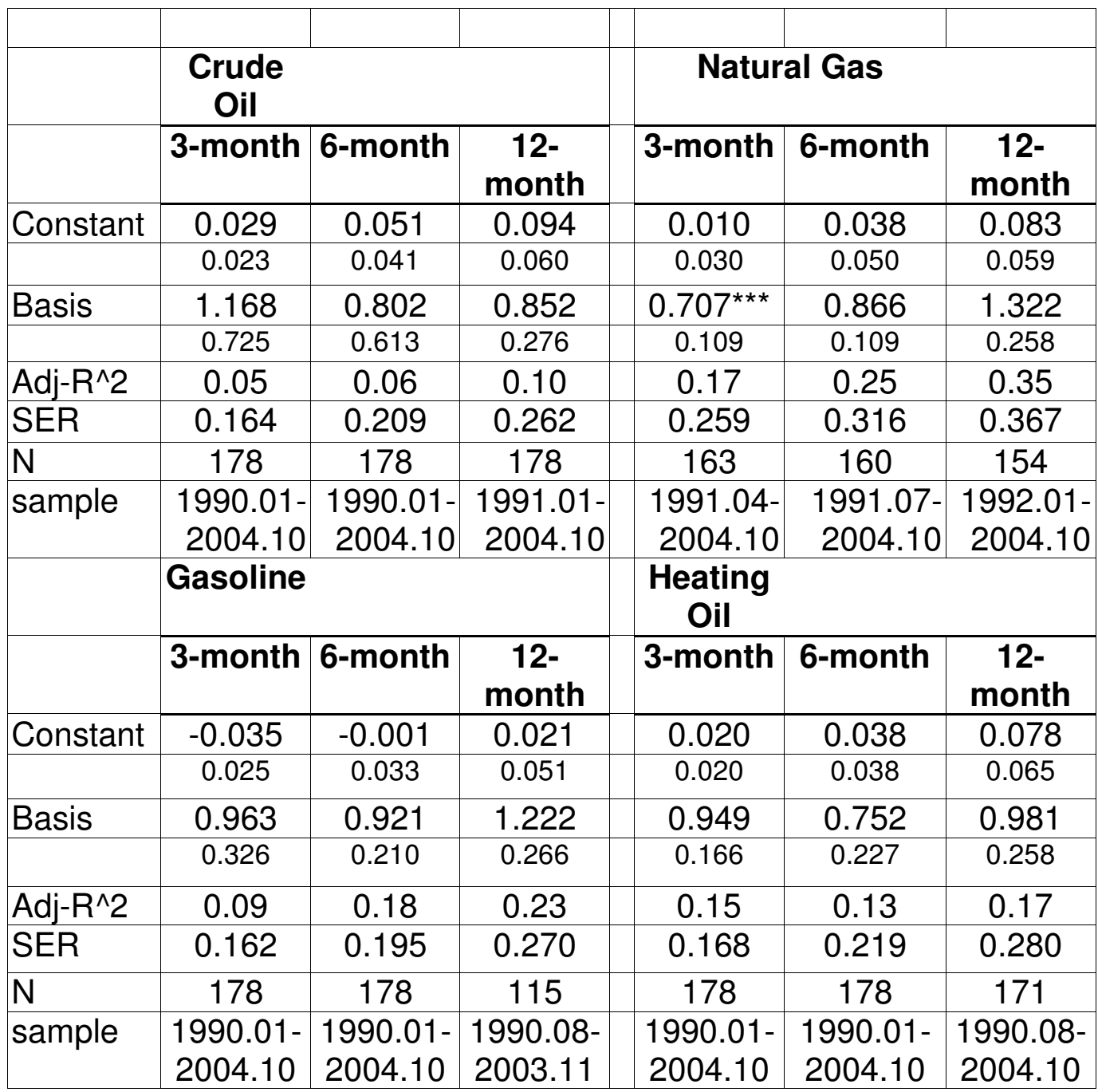

Notes: Regression of ex post change on basis (see equation 2).

Estimation via OLS, using Newey-West heteroskedasticity and serial correlation robust standard errors, lag order set to $2(\mathrm{k}-1)$. * $(* *)[* * *]$ denotes coefficient is different from unity at the 10(5)[1] percent marginal significance level. 
Table 2

Forecast Comparison

Actual minus predicted over 1999.01-2004.10 period

\begin{tabular}{|c|c|c|c|c|}
\hline \multicolumn{2}{|l|}{ Oil } & 3 month & 6 month & 12 month \\
\hline \multirow[t]{2}{*}{$\overline{\text { Futures }}$} & $\mathrm{ME}$ & 0.078 & 0.149 & 0.241 \\
\hline & RMSE & $\underline{0.146}$ & $\underline{0.195}$ & $\underline{0.265}$ \\
\hline \multirow{2}{*}{$\begin{array}{l}\text { Random } \\
\text { Walk }\end{array}$} & $\mathrm{ME}$ & 0.057 & 0.101 & 0.169 \\
\hline & RMSE & $\overline{0.153}$ & 0.207 & 0.303 \\
\hline \multirow[t]{2}{*}{ ARIMA } & $\mathrm{ME}$ & 0.058 & 0.072 & 0.124 \\
\hline & RMSE & 0.185 & 0.237 & $\overline{0.350}$ \\
\hline \multicolumn{2}{|c|}{ Natural Gas } & 3 month & 6 month & 12 month \\
\hline \multirow[t]{2}{*}{ Futures } & $\bar{M} \mathrm{E}$ & 0.017 & 0.058 & 0.143 \\
\hline & RMSE & 0.282 & $\overline{0.373}$ & $\underline{0.441}$ \\
\hline \multirow{2}{*}{$\begin{array}{l}\text { Random } \\
\text { Walk }\end{array}$} & $\mathrm{ME}$ & 0.051 & 0.101 & 0.180 \\
\hline & RMSE & 0.296 & 0.426 & 0.553 \\
\hline \multirow[t]{2}{*}{ ARIMA } & $\mathrm{ME}$ & 0.051 & 0.081 & $\underline{0.120}$ \\
\hline & RMSE & 0.324 & 0.454 & $\overline{0.575}$ \\
\hline \multicolumn{2}{|l|}{ Gasoline } & 3 month & 6 month & 12 month \\
\hline \multirow[t]{2}{*}{$\overline{\text { Futures }}$} & $\mathrm{ME}$ & 0.001 & 0.071 & 0.104 \\
\hline & RMSE & 0.172 & 0.196 & $\overline{0.272}$ \\
\hline \multirow{2}{*}{$\begin{array}{l}\text { Random } \\
\text { Walk }\end{array}$} & $\mathrm{ME}$ & 0.056 & 0.104 & 0.170 \\
\hline & RMSE & 0.188 & 0.239 & 0.317 \\
\hline \multirow[t]{2}{*}{ ARIMA } & $\mathrm{ME}$ & 0.068 & 0.087 & 0.128 \\
\hline & RMSE & 0.214 & 0.269 & 0.378 \\
\hline \multicolumn{2}{|c|}{ Heating Oil } & 3 month & 6 month & 12 month \\
\hline \multirow[t]{2}{*}{ Futures } & $\mathrm{M} E$ & 0.075 & 0.136 & 0.213 \\
\hline & RMSE & $\underline{0.172}$ & 0.221 & 0.302 \\
\hline \multirow{2}{*}{$\begin{array}{l}\text { Random } \\
\text { Walk }\end{array}$} & $\mathrm{ME}$ & 0.057 & 0.102 & 0.168 \\
\hline & RMSE & $\overline{0.196}$ & $\overline{0.249}$ & 0.366 \\
\hline \multirow[t]{2}{*}{ ARIMA } & $\mathrm{ME}$ & 0.064 & 0.080 & 0.118 \\
\hline & RMSE & 0.220 & 0.278 & $\overline{0.433}$ \\
\hline
\end{tabular}

Notes: ME: Mean forecast error. RMSE: Root mean forecast error. The random walk is assumed to have no drift term. An ARIMA $(1,1,1)$ is used for the spot prices. Bold face underlined entries indicate the best performance. 


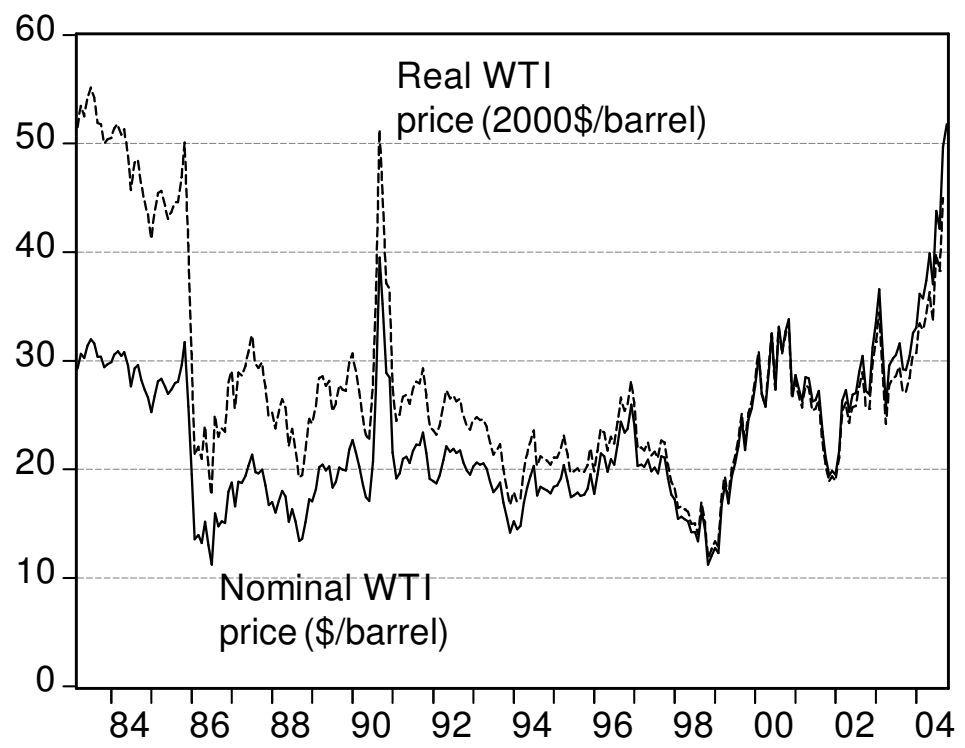

Figure 1: Price of Petroleum, nearest month. Source: Bloomberg.

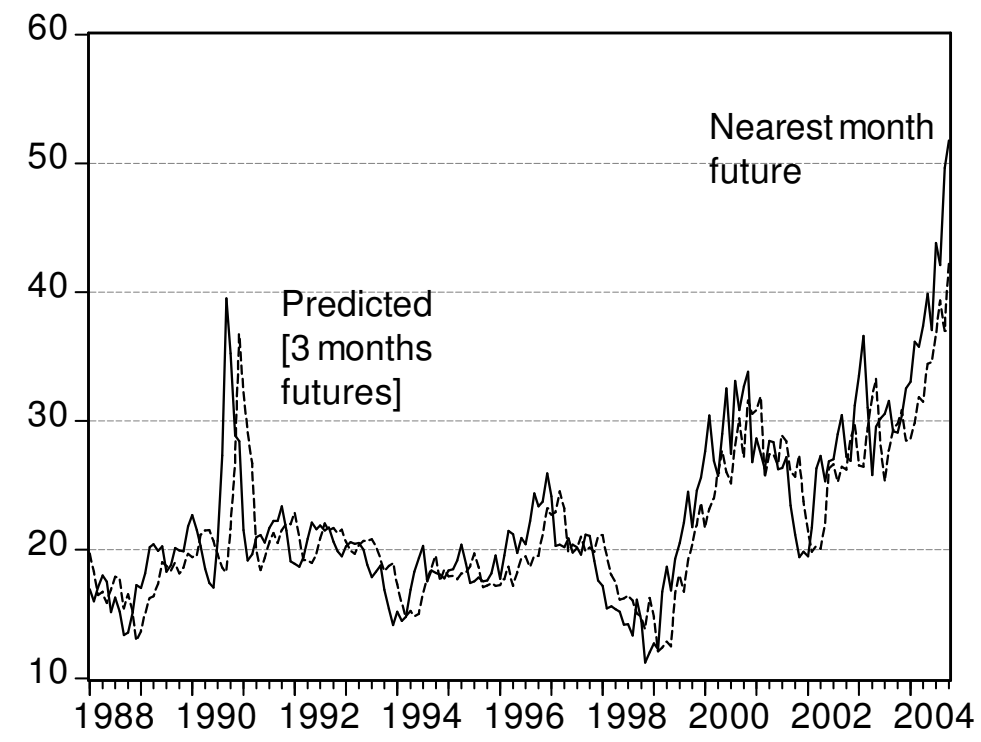

Figure 2: Price of Petroleum (WTI), end of month, and price predicted by 3 month futures. 


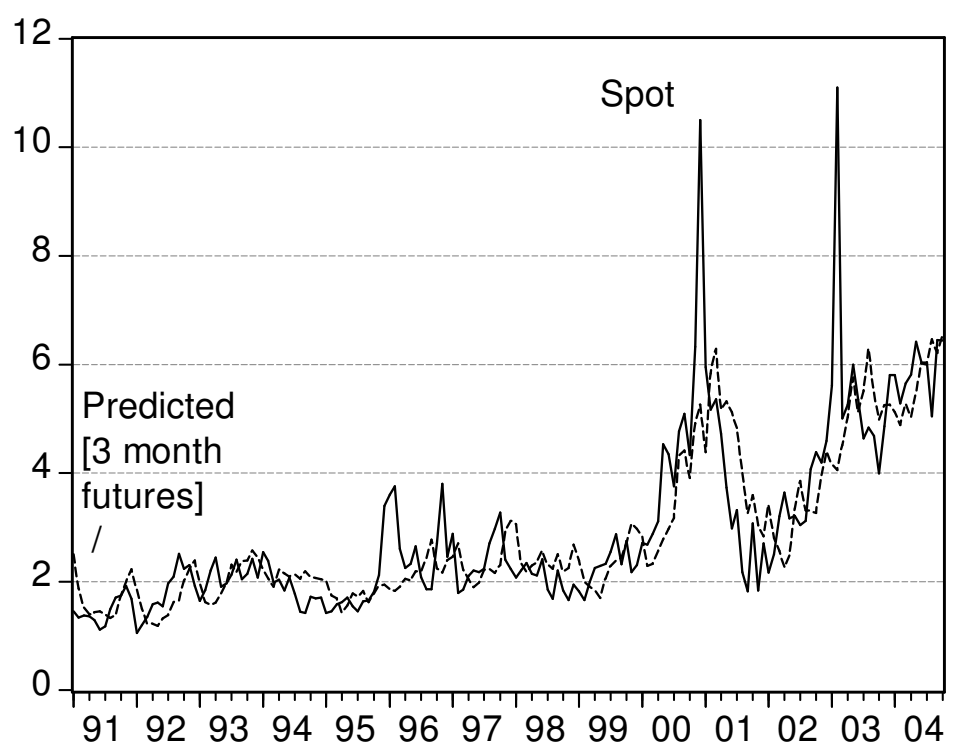

Figure 3: Price of Natural Gas (Henry Hub), end of month, and price predicted by 3 month futures.

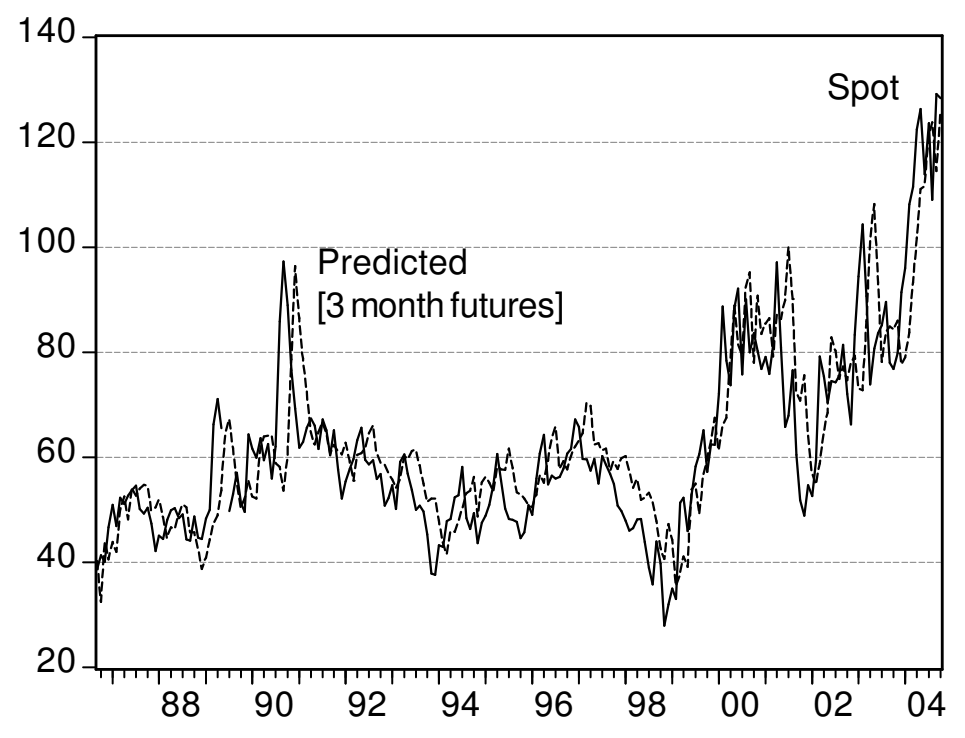

Figure 4: Price of Gasoline (NY Harbor), end of month, and price predicted by 3 month futures. 


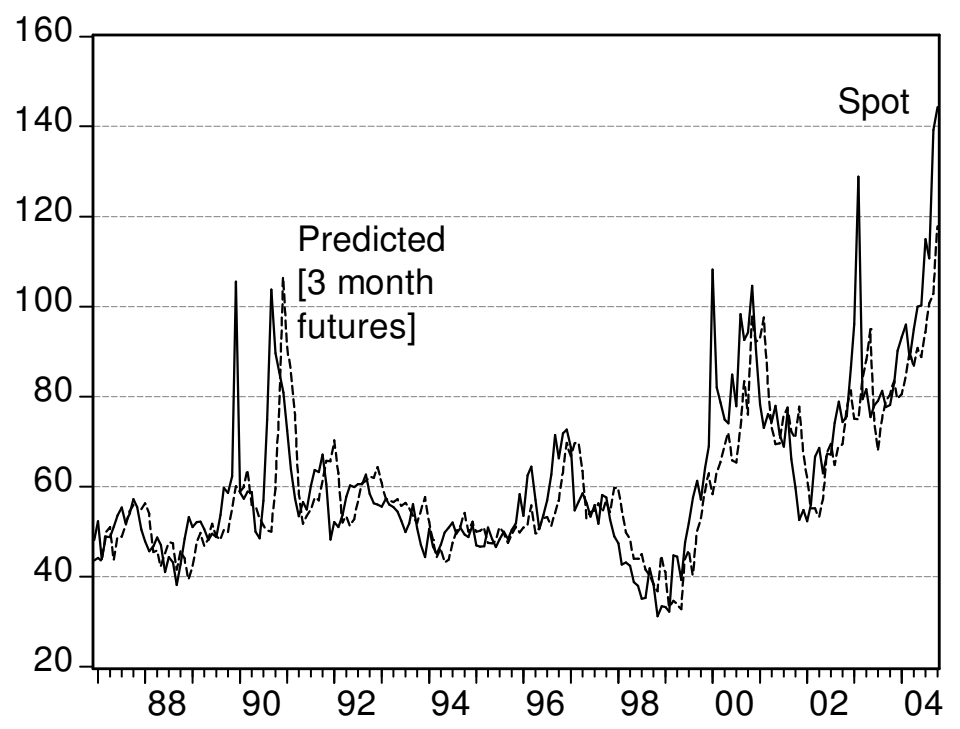

Figure 5: Price of Heating Oil, end of month, and price predicted by 3 month futures.

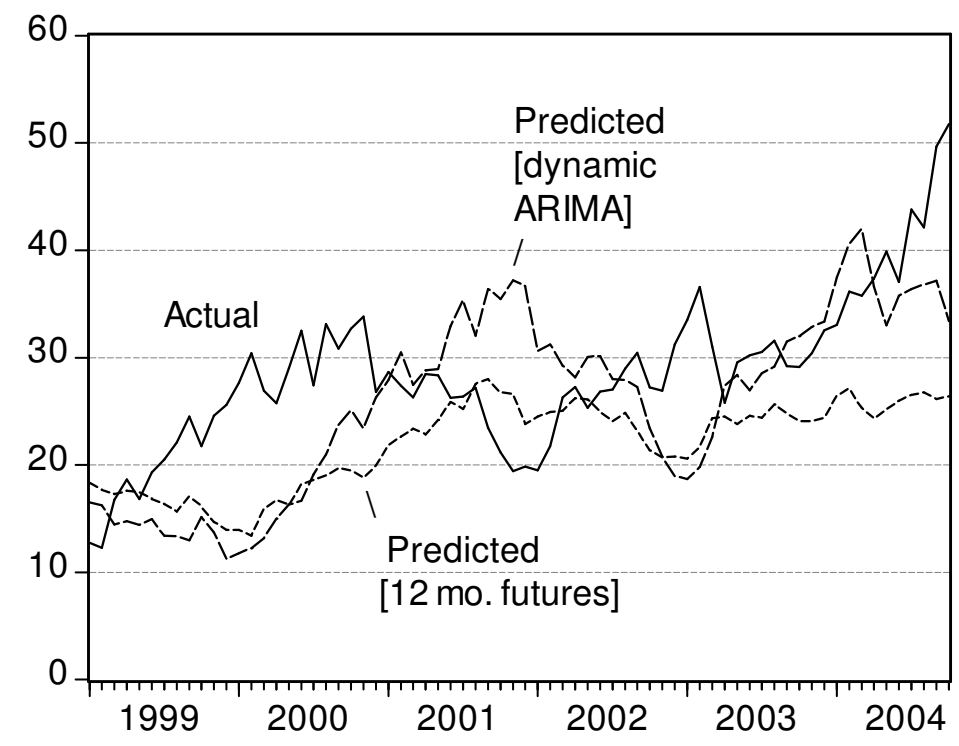

Figure 6: Price of Petroleum and Forecasts from 12 month futures and ARIMA(1,1,1) model. 